\title{
A New 2D Framework Based on 2,3'-Bipyridine-2',3-dicarboxylate Copper(II) Units: Synthesis, Structure and Photoluminescence Properties
}

\author{
Kamil Twaróg ${ }^{1}$ Małgorzata Hołyńska ${ }^{2}$. Andrzej Kochel ${ }^{1}$
}

Received: 10 October 2017 / Accepted: 19 December 2017 / Published online: 3 January 2018

(C) The Author(s) 2018. This article is an open access publication

\section{Abstract}

A new ligand 2,3'-bipyridine-2',3-dicarboxylic acid monohydrate (1) and a new copper(II) 2D coordination polymer [Cu(2,3'$\left.\left.2^{\prime}, 3-\mathrm{bpdc}\right) \mathrm{H}_{2} \mathrm{O}\right]_{\mathrm{n}}(2)\left(2,3^{\prime}-2^{\prime}, 3-\right.$ bpdc $=$ deprotonated bipyridinedicarboxylic acid $)$ were synthesized and characterized by X-ray diffraction studies, IR spectra, elemental analysis, EPR, luminescence spectra and TGA. Magnetic properties measurements show weak antiferromagnetic coupling of the metal ions in the copper compound. These interactions are most likely assisted by hydrogen bonds.

\section{Graphical Abstract}

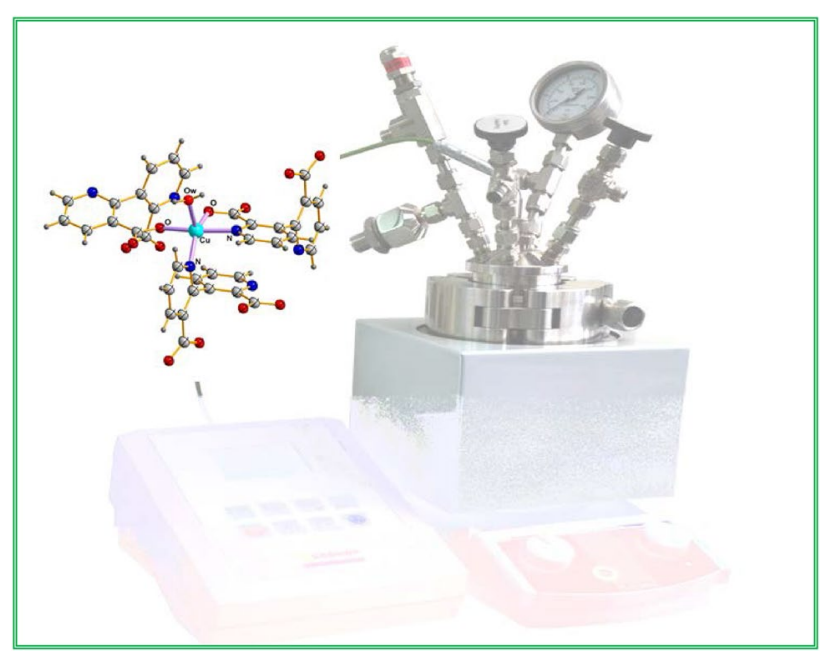

Keywords Coordination polymers · Copper(II) $\cdot$ Crystal structures $\cdot$ TGA $\cdot$ Magnetic properties $\cdot$ Fluorescent properties

Electronic supplementary material The online version of this article (https://doi.org/10.1007/s10904-017-0774-7) contains supplementary material, which is available to authorized users.

Małgorzata Hołyńska

holynska@chemie.uni-marburg.de

$\square$ Andrzej Kochel

andrzej.kochel@chem.uni.wroc.pl

Extended author information available on the last page of the article

\section{Introduction}

Aminocarboxyl ligands can act as precursors of metal coordination polymers. Coordination polymers (CPs) are a thriving class of functional solid-state materials that have attracted much attention due to their potential use in various key applications, among them storage/separation, catalysis, molecular magnetism and non-linear optics [1]. 
In our previous work we described a $2 \mathrm{D}$ coordination polymer with aminocarboxylate 3,3'-bipyridine2,2'-dicarboxylate $\left(3,3^{\prime}\right.$-bpdc) ligand, $\left[\mathrm{Mn}\left(3,3^{\prime} \text {-bpdc }\right)\right]_{\mathrm{n}}$ [2]. Two new coordination polymers employing 2,2'-bipyridine-3, 3',6,6'-tetracarboxylate (bptc) as a ligand were also presented: $\left[\mathrm{Mn}_{2}\left(\mathrm{H}_{2} \mathrm{O}\right)_{5}(\mathrm{bptc})\right]_{\mathrm{n}}$ is a $2 \mathrm{D}$ coordination polymer stabilized by $\mathrm{Mn}-\mathrm{O}$ coordination bonds, where magnetic interactions are transmitted within carboxylate bridged chains showing weak antiferromagnetic interactions and $\left[\mathrm{Cu}_{2}\left(\mathrm{H}_{2} \mathrm{O}\right)_{2}(\mathrm{bptc})\right]_{\mathrm{n}} \cdot 2 \mathrm{nH}_{2} \mathrm{O}$ forms polymeric double chains [3].

Sanram et al. obtained a series of $\mathrm{Cu}$ (II) MOFs using 1,4-phenylenedipropionic acid and different $\mathrm{N}, \mathrm{N}^{\prime}$-donor coligands, namely, $[\mathrm{Cu}(\mathrm{ppa})(\mathrm{bpy})]_{\mathrm{n}}(\mathbf{1}),\{[\mathrm{Cu}(\mathrm{ppa})($ azp $)$ $\left.\left.\left(\mathrm{H}_{2} \mathrm{O}\right)\right]\left(\mathrm{H}_{2} \mathrm{O}\right)\right\}_{\mathrm{n}}(2),\left(\mathrm{H}_{2} \mathrm{ppa}=1,4-\right.$ phenylenedipropionic acid, bpy $=4,4^{\prime}$-bipyridine, azp $=4,4^{\prime}$-azobipyridine). The compound 4 is transformed from compound 3 by heating, through single-crystal-to-single-crystal transformation, adopting a $\mathrm{CdSO}_{4}$-like (cds) 3D framework. All products were characterized with respect to their photocatalytic properties [4].

Other researchers used $\mathrm{Cu}\left(\mathrm{NO}_{3}\right)_{2} \cdot 3 \mathrm{H}_{2} \mathrm{O}$ as a substrate in hydrothermal syntheses to obtain MOFs with polycatenation and polythreading leading to $2 \mathrm{D}$ square grids $\left[\mathrm{Cu}(\mathrm{II})_{2}(5-\mathrm{HIPA})_{2}\left(4,4^{\prime} \text {-bipy }\right)_{2}\left(\mathrm{H}_{2} \mathrm{O}\right)_{2}\right]_{n}(\mathbf{A}$, 5-HIPA $=5$-hydroxyisophthalato) and irregular layers $\left[\mathrm{Cu}(\mathrm{II})_{3}(5 \text {-HIPA })_{2}(2-\mathrm{PyC})_{2}\left(4,4^{\prime} \text {-bipy }\right)_{2}\left(\mathrm{H}_{2} \mathrm{O}\right)_{4}\right]_{n}$ (B) in a unique $3 \mathrm{D}$ framework $[(\mathbf{A})(\mathbf{B})] \cdot 6.5 n \mathrm{H}_{2} \mathrm{O}(\mathbf{1})$ with the in situ generated pyridine-2-carboxylate (2-PyC) ligand [5].

In 2014 Sasmal et al. obtained two $\mathrm{Cu}(\mathrm{II})$ coordination polymers $\left\{[\mathrm{Cu}(\mathrm{HPymat})(\mathrm{MeOH})]\left(\mathrm{NO}_{3}\right)\right\}_{n}(\mathbf{1})$ and $\left\{\left[\mathrm{Cu}_{4}(\mathrm{Pymab})_{4}\left(\mathrm{H}_{2} \mathrm{O}\right)_{4}\right]\left(\mathrm{NO}_{3}\right)_{4}\right\}$ (2). Schiff-base ligands HPymat $^{-}$and Pymab ${ }^{-}\left[\mathrm{H}_{2}\right.$ Pymat $=(E)-2-(1-($ pyridin2-yl)methyleneamino)terephthalic acid, $\mathrm{HPymab}=(E)$ 2-((pyridine-2-yl)methyleneamino)benzoic acid] were used as substrates. The compound $\mathbf{1}$ shows tetragonal EPR spectra in DMSO and DMF and inverse EPR spectrum in $\mathrm{CH}_{3} \mathrm{CN}$. The complex (2) shows rhombic EPR spectra in solid state at RT and $77 \mathrm{~K}$ and tetragonal spectra in DMSO, DMF and $\mathrm{CH}_{3} \mathrm{CN}$ [6].

In Table 1 these compounds are classified with respect to ligand type and ligand coordination modes. The title copper(II) compound belongs to 2D frameworks with $\mathrm{N}, \mathrm{O}$-donor ligands.

Thus in this paper a new $2 \mathrm{D}$ coordination polymer is introduced, showing an interesting coordination mode for pyridine carboxylate ligand. Both ligand and the corresponding polymer are photoluminescent.

\section{Experimental Section}

\subsection{General}

Double-distilled water was used and $\mathrm{Cu}\left(\mathrm{BF}_{4}\right)_{2} \cdot \mathrm{H}_{2} \mathrm{O}$ was purchased and used as received.

\subsection{Synthesis}

\subsubsection{2,3' '-Bipyridine-2' 3 3-dicarboxylic Acid Monohydrate}

A $100 \mathrm{~cm}^{3}$ round-bottom flask was equipped with a reflux condenser and filled with $60 \mathrm{~cm}^{3}$ of water. $1.00 \mathrm{~g}$ $(0.180 \mathrm{mmol})$ of 1,7 -phenanthroline and $0.4032 \mathrm{~g}$ $(0.100 \mathrm{mmol}) \mathrm{NaOH}$ were added. The mixture was stirred for $15 \mathrm{~min}$. Subsequently, $1.3941 \mathrm{~g}(0.876 \mathrm{mmol})$ of $\mathrm{KMnO}_{4}$ was added in small portions and rinsing the corresponding weighing vessel with additional $10 \mathrm{~cm}^{3}$ of water. The mixture was heated in oil bath and stirred at $95-97^{\circ} \mathrm{C}$ for $10 \mathrm{~h}$. The obtained solution was filtered from the $\mathrm{MnO}_{2}$ side-product. Then active carbon was added and the suspension was heated at $95-97{ }^{\circ} \mathrm{C}$ for about $1 \mathrm{~h}$. The mixture was filtered and left for cooling. The $\mathrm{pH}$ of the cool solution was adjusted to $3-4$ by addition of $3 \mathrm{M} \mathrm{HCl}$ dropwise. The obtained solution was left at room temperature for slow evaporation. After 2 days crystals in form of large plates suitable for X-ray diffraction studies were formed at $65 \%$ yield. The photographs with the single crystals of $\mathbf{1}$ are added in Fig. S6 in the Supplementary Material.

\subsection{2 $\left[\mathrm{Cu}\left(2,3^{\prime}-2^{\prime}, 3-\text { bpdc }\right) \mathrm{H}_{2} \mathrm{O}\right]_{n}(2)$}

$0.100 \mathrm{~g}(0.381 \mathrm{mmol})$ of $(\mathbf{1}), 10 \mathrm{ml}$ of water and $\mathrm{Cu}\left(\mathrm{BF}_{4}\right)_{2} \cdot \mathrm{H}_{2} \mathrm{O}$ of $(0.06 \mathrm{~g}, 0.234 \mathrm{mmol})$ were combined and sealed in a steel Teflon-lined Berghoff 100 autoclave. The use of stainless steel Berghoff autoclave allows for a one-pot synthesis of pure crystalline magnetic materials. Control of pressure (up to $100 \mathrm{bar}$ ) and temperature (up to $300{ }^{\circ} \mathrm{C}$ ) in this setup ensures stable synthesis conditions and its reproducibility. The use of organic ligands narrows the synthesis temperature range to typically $100-300{ }^{\circ} \mathrm{C}$, based on melting and decomposition points. The reagents are added in a Teflon insert. An advantage of solvothermal synthesis is the possibility to use reagents and solvents in which they are insoluble under normal conditions-for instance this advantage can be used to obtain $\left(\mathrm{NH}_{4}\right)_{2}\left[\mathrm{Re}(\mathrm{NCS})_{6}\right] \cdot 4\left(\mathrm{CH}_{3}\right)_{2} \mathrm{SO}_{2}$ product from dimethyl sulphone [7]. Organic solvents, such as alcohols and acetonitrile, are widely used but at limited scale due to safety 
Table 1 Different types of metal-organic frameworks with N, O-donor ligands and various dimensionality

$\mathrm{N}, \mathrm{O}$-donor atoms in one ligand

$\left[\mathrm{Cu}_{2}\left(\mathrm{H}_{2} \mathrm{O}\right)_{2}(\mathrm{bptc})_{] \mathrm{n}} \cdot 2 \mathrm{nH}_{2} \mathrm{O}[1]\right.$

$\left\{[\mathrm{Cu}(\mathrm{HPymat})(\mathrm{MeOH})]\left(\mathrm{NO}_{3}\right)\right\}_{\mathrm{n}}[6]$
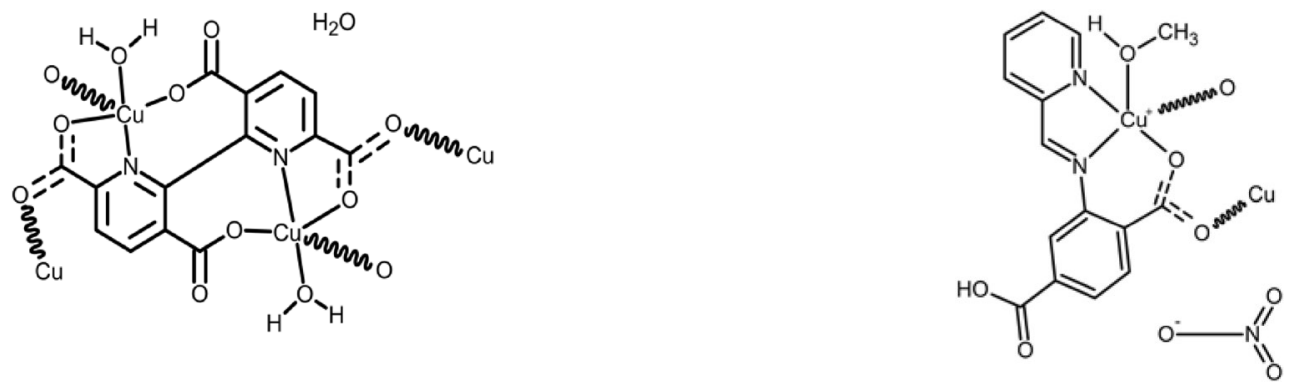

$\left.\left[\mathrm{Cu}_{4}(\mathrm{Pymab})_{4}\left(\mathrm{H}_{2} \mathrm{O}\right)_{4}\right]\left(\mathrm{NO}_{3}\right)_{4}\right\}[6]$

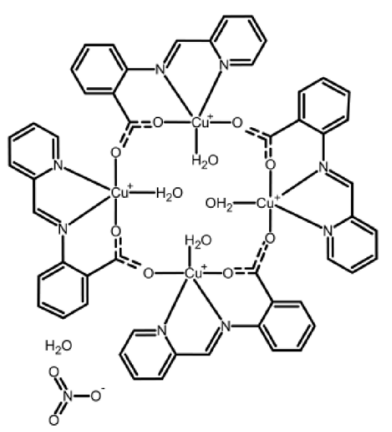

$\mathrm{N}, \mathrm{O}$-donor atoms in separate ligands

$\left\{\left[\mathrm{Cu}(\mathrm{ppa})(\operatorname{azp})\left(\mathrm{H}_{2} \mathrm{O}\right)\right]\left(\mathrm{H}_{2} \mathrm{O}\right)\right\}_{\mathrm{n}}[4]$

$[\mathrm{Cu}(\mathrm{ppa})(\mathrm{bpy})]_{\mathrm{n}}[4]$
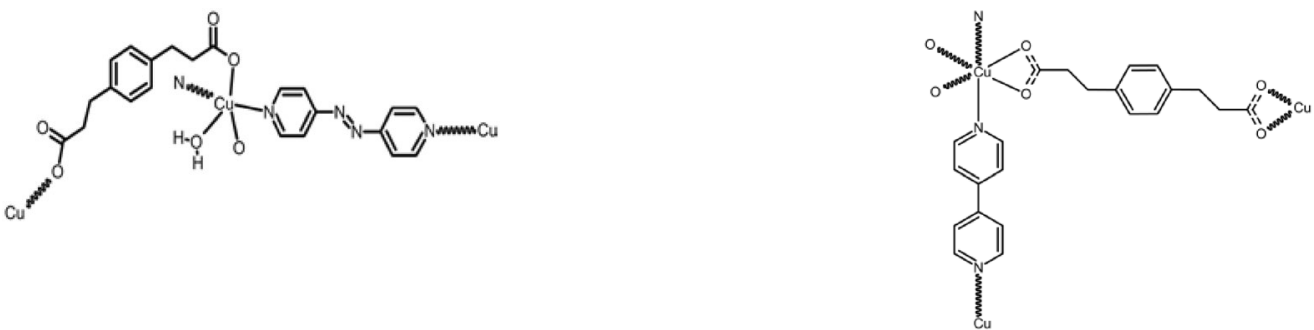
Table 1 (continued)

$\mathrm{N}$, O-donor atoms in separate ligands

$\left[\mathrm{Cu}(\mathrm{II})_{3}(5-\mathrm{HIPA})_{2}(2-\mathrm{PyC})_{2}\left(4,4^{\prime} \text {-bipy }\right)_{2}\left(\mathrm{H}_{2} \mathrm{O}\right)_{4}\right]_{\mathrm{n}}[5]$

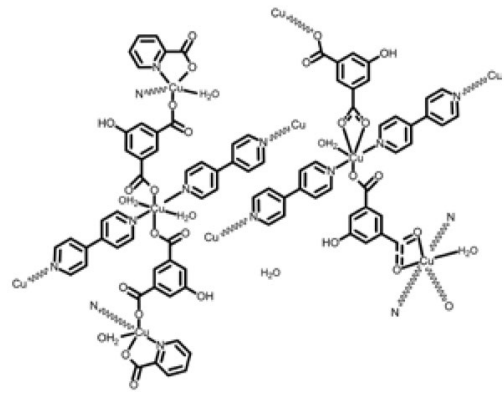

$\left[\mathrm{Cu}(\mathrm{II})_{2}(5-\mathrm{HIPA})_{2}\left(4,4^{\prime} \text {-bipy }\right)_{2}\left(\mathrm{H}_{2} \mathrm{O}\right)_{2}\right]_{\mathrm{n}}[5]$

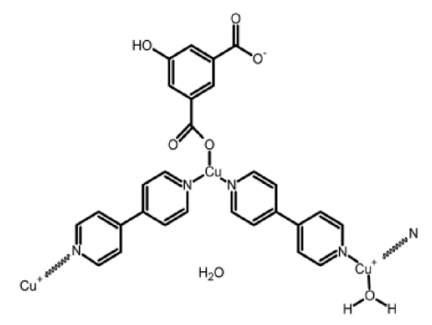

issues. After the synthesis the reaction mixture cools down very slowly which promotes crystallization of the product.

The mixture was heated at $135^{\circ} \mathrm{C}$ for 5 days and subsequently slowly cooled down at $8{ }^{\circ} \mathrm{C} / \mathrm{h}$ within $24 \mathrm{~h}$. The resulting product comprised crystalline material with single crystals in form of blue prisms at $45 \%$ yield (estimated with respect to the 2,3'-bipyridine-2',3-dicarboxylic acid monohydrate reagent for the crystalline products directly crystallized from the reaction mixture). The pictures with the single crystals of $\mathbf{2}$ are added in Fig. S7 in the Supplementary Material.

\subsection{Characterization}

\subsubsection{IR Spectroscopy}

2.3.1.1 IR Spectra were recorded with Bruker VERTEX 70 FTIR spectrometer for $\mathbf{1}$ and $\mathbf{2}$. Selected bands from IR and spectra are presented as Supplementary Data S1, S2, Figs. S1a, b, S2a, b.

\subsubsection{Elemental Analyses}

2.3.2.1 CHN Elemental 1: Obs (Calcd for) \%C 54.01 (54.96), \% H 4.05 (4.40), \% 10.55 (10.68); 2 Obs (Calcd for): \%C 44.23 (44.51), \% 2.51 (2.66), \%N 8.43 (8.65).

\subsubsection{Thermogravimetric Analyses}

2.3.3.1 TGA Measurements were carried out on a SETARAM SetSys 16/18 TG-DTA device under nitrogen atmosphere with scanning rate at $10 \mathrm{~K} / \mathrm{min}$. for samples of $1(13.63 \mathrm{mg})$ and $2(6.15 \mathrm{mg})$ in the temperature range 40-1200 ${ }^{\circ} \mathrm{C}$ (see Supplementary Fig. S4 for 1, Fig. S5 for 2).

\subsubsection{X-ray Diffraction Studies and Details of the Structures Refinement}

2.3.4.1 X-ray Diffraction X-ray diffraction data for monocrystals of $\mathbf{1}$ and $\mathbf{2}$ were collected on an Xcalibur Ruby and KM4CCD Sapphire diffractometer [8] with $\mathrm{MoK}_{\alpha}$ radiation at 100(2) K. Selected X-ray data are shown in Tables S1-S4 for 1 and 2 (ESI). CCDC reference numbers for 1 and 2: CCDC 1543112 (1) and 1547821 (2) (Supplementary Data available from CCDC, 12 Union Road, Cambridge $\mathrm{CB} 2,1 \mathrm{EZ}, \mathrm{UK}$ on request).

2.3.4.2 Crystal Structures Refinement The crystal structures were solved with direct methods in SHELXTL and refined using the full-matrix method in SHELXL [9]. Water/hydroxyl $\mathrm{H}$ atoms positions were initially refined with DFIX restraints (the $\mathrm{O}-\mathrm{H}$ bond lengths at $0.84 \AA$ and with $\mathrm{U}_{\mathrm{eq}}=1.5 \mathrm{U}_{\mathrm{eq}}$ (parent atom). Then these $\mathrm{H}$ atoms parameters were constrained. $\mathrm{H}$ atoms bonded to aromatic $\mathrm{C}$ atoms were generated using HFIX instuction with $\mathrm{U}_{\mathrm{eq}}=1.2-1.5 \mathrm{U}_{\mathrm{eq}}$ (parent $\mathrm{C}$ atom). Basic crystallographic data and selected bond lengths and bond angles are presented in the Supplementary Tables S2-S4.

\subsubsection{EPR Spectra}

EPR spectra were recorded at $77 \mathrm{~K}$ on a Bruker ELEXSYS E 500 CW-EPR spectrometer operating at X-band frequency and equipped with an ER 036TM NMR Teslameter and E 41 FC frequency counter. Spectra were measured at microwave power of $10 \mathrm{~mW}$, modulation amplitude of $10 \mathrm{G}$ and time constant $40 \mathrm{~ms}$. The experimental spectra were simulated using the Bruker Win EPR SimFonia program, version 1.26 [10]. 


\subsubsection{Photoluminescence Spectra}

The photoluminescence spectra of $\mathbf{1}$ and $\mathbf{2}$ for solid crystalline samples anchored to quartz tubes were recorded with an FSL 980 Spectrometer from Edinburgh Instrument equipped with a $450 \mathrm{~W}$ Xenon arc lamp as an excitation source.

\subsubsection{Studies of the Magnetic Properties}

2.3.7.1 Magnetic Properties Magnetic susceptibility data were recorded on a Quantum Design MPMS-XL5 SQUID magnetometer over the 300-1.8 K temperature range. Magnetic data were corrected for diamagnetic contributions which were estimated from the Pascal's constants [11] and for temperature-independent paramagnetism estimated at $60 \times 10^{-6} \mathrm{emu} / \mathrm{mol}$ for the $\mathrm{Cu}^{2+}$ ion [12].

\subsubsection{NMR Spectra}

NMR spectra were recorded on Bruker $500 \mathrm{MHz}$ device.

For 1 see Supplementary Fig. S1 ( ${ }^{1} \mathrm{H}$ NMR spectrum, $\left.500 \mathrm{MHz}, \mathrm{D}_{2} \mathrm{O}, 300 \mathrm{~K}\right)$, Fig. S2 $\left({ }^{13} \mathrm{C}\right.$ NMR spectrum, $\left.125 \mathrm{MHz}, \mathrm{D}_{2} \mathrm{O}, 300 \mathrm{~K}\right)$, Fig. S3 (2D spectra ${ }^{1} \mathrm{H}-{ }^{1} \mathrm{H}$ COSY, $\left.500 \mathrm{MHz}, \mathrm{D}_{2} \mathrm{O}, 300 \mathrm{~K}\right)$.

\section{Results and Discussion}

\subsection{Syntheses}

The synthesis of the ligand is illustrated in Scheme 1. $\mathrm{KMnO}_{4}$ was used as an oxidizer and the $\mathrm{MnO}_{2}$ side-product was filtered off from the reaction mixture. The amount of oxidizer was optimized to result in the highest yield. It should be emphasized that too high excess of the oxidizer may lead to further oxidation of the product. Scheme 1 summarizes the ligand synthesis (Schemes 1,2).

2 is obtained in solvothermal syntheses from the following systems under hydrothermal conditions in the Berghoff autoclave.

The product was isolated in the pure crystalline form. Coordination modes displayed by the ligand are shown in the Scheme 3.

\subsection{Analysis of the Crystal Structures}

\subsubsection{2,3' '-Bipyridine-2' ${ }^{\prime}$ 3-dicarboxylic Acid (1) Crystal Structure Determination}

2,3'-Bipyridine-2',3-dicarboxylic acid (1) molecule comprises two pyridyl rings with $\mathrm{N}$ atoms at $2,3^{\prime}$ positions and

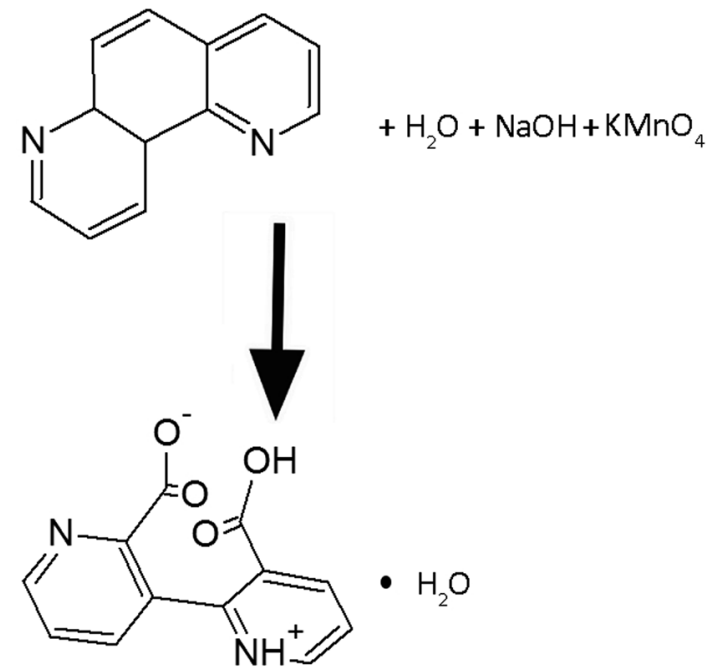

Scheme 1 Synthesis of the ligand $\left(2,3^{\prime}-2^{\prime}, 3-b p d c\right) \cdot \mathrm{H}_{2} \mathrm{O}$

two carboxylic groups substituting each of the aromatic rings. Molecular structure is shown in Fig. 1.

The torsion angle $\mathrm{C} 5-\mathrm{C} 11-\mathrm{C} 10-\mathrm{C} 6$ is of $72.60(17)^{\circ}$ and describes the relative orientation of the carboxylic groups. The molecule adopts a zwitterion form with protonated $\mathrm{N}$ atom and de-protonated carboxylic group. Such zwitterionic form was also observed for 2,2'-bipyridine-4-methyl3,3'-dicarboxylic acid monohydrate [13] and for rac-4,4'bipyridine-2,2'-dicarboxylic acid monohydrate [14]. All of these zwitterionic compounds were isolated from aqueous solutions with neutral $\mathrm{pH}$. The crystal structure of $\mathbf{1}$ is stabilized by a 3D hydrogen bonding network. The parameters of the corresponding hydrogen bonds are listed in Supplementary Table S5.

Extended hydrogen bonding network includes such graph set motifs as $D_{3}^{3}(12), D_{3}^{3}(18), R_{4}^{4}(14)$. Figure 2 illustrates one of such motifs.

\subsubsection{D Coordination Polymer Framework $\left[\mathrm{Cu}\left(2,3^{\prime}-2^{\prime}, 3-\text { bpdc }\right) \mathrm{H}_{2} \mathrm{O}\right]_{n}(2)$}

The coordination polymer $\mathbf{2}$, similarly as the ligand $\mathbf{1}$, crystallizes in monoclinic space group type $\mathrm{P} 2{ }_{1} / \mathrm{c}$ (basic crystallographic data are summarized in the Supplementary Material). In the asymmetric unit of the unit cell one ligand molecule is coordinated to the $\mathrm{Cu}^{2+}$ ion. In the coordination sphere also a terminal water molecule is present (Fig. 3).

The coordination number of the $\mathrm{Cu}^{2+}$ ion in $\mathbf{2}$ is 5 . The coordination sphere is filled with 3 ligands: one is coordinated through $\mathrm{N}$ and carboxyl $\mathrm{O}$ atoms, the second ligandthrough pyridine $\mathrm{N}$ atom and the third ligand through carboxyl $\mathrm{O}$ atom. The fifth coordination place is filled with the terminal water molecule (see Fig. 4). 


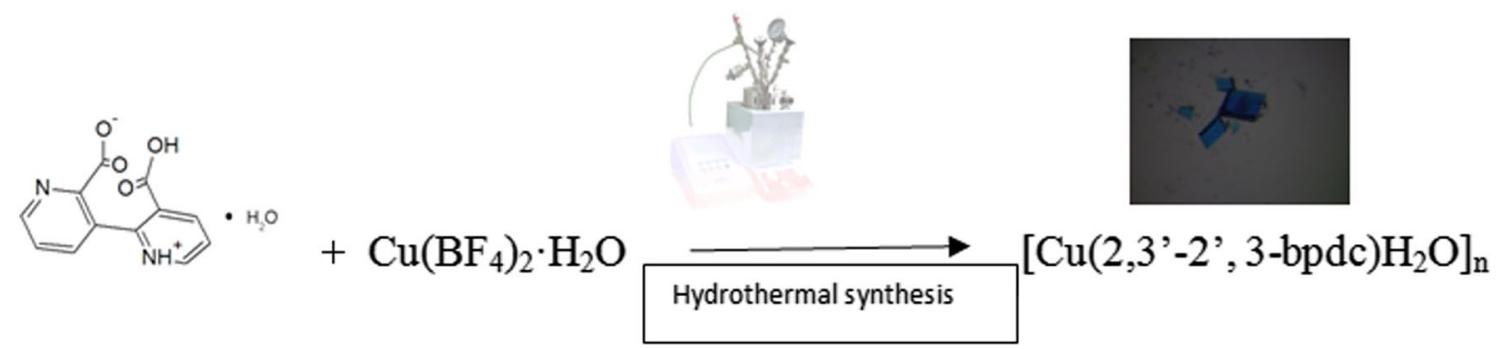

Scheme 2 Hydrothermal synthesis of $\left[\mathrm{Cu}\left(2,3^{\prime}-2^{\prime}, 3-b p d c\right) \mathrm{H}_{2} \mathrm{O}\right]_{n}(2)$

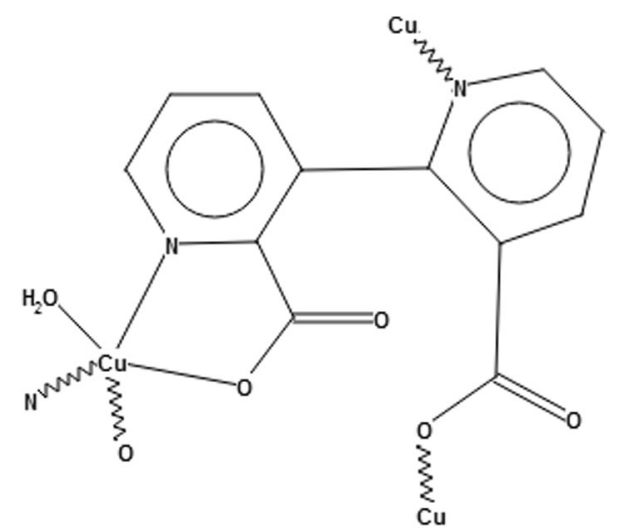

Scheme 3 Coordination modes displayed by the ligand in the compound 2

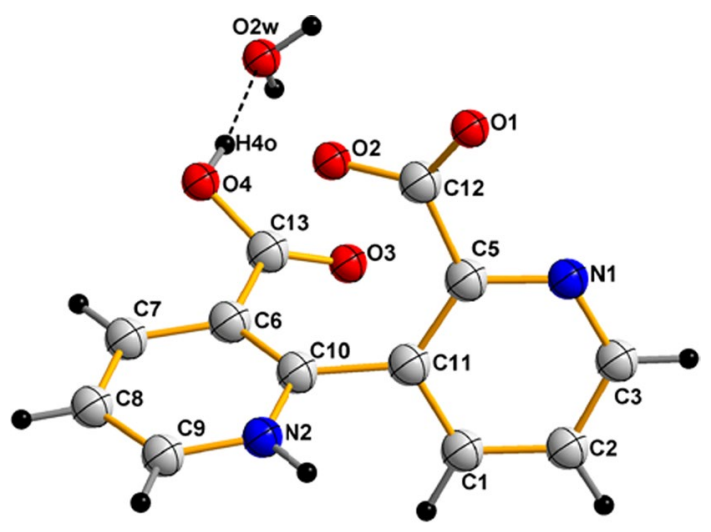

Fig. 1 Molecular structure of $\mathbf{1}$. Hydrogen bonding is denoted with a dashed line

The corresponding bond lengths are $\mathrm{Cu} 1-\mathrm{O} 1$ 1.985(3), Cu1-N1 1.999(4), Cu1-O1w 2.180(3) $\AA$ and $\mathrm{Cu} 1-\mathrm{O} 3(-\mathrm{x}+1, \mathrm{y}-0.5,-\mathrm{z}+0.5) 1.933(3), \mathrm{Cu} 1-\mathrm{N} 2$ $(-x+1,-y,-z+1) 2.059(4)$. Similar bond lengths for terminal water ligand coordinated to a $\mathrm{Cu}^{2+}$ ion were also determined by Li-Yang Zhang et al. for a 2D coordination polymer $\left[\mathrm{Cu}^{\mathrm{II}} \mathrm{Cu}_{2}^{\mathrm{I}}(\mathrm{HPIDC})_{2}\left(\mathrm{H}_{2} \mathrm{O}\right)\right]_{\mathrm{n}}$ in which the $\mathrm{Cu}-\mathrm{H}_{2} \mathrm{O}$ bond length is of 2.2200(16) $\AA$ [15].

Also for another coordination polymer, $[\mathrm{Cu}(6-$ mepic $\left.)_{2}\left(\mathrm{H}_{2} \mathrm{O}\right)\right] \cdot \mathrm{H}_{2} \mathrm{O}$, the $\mathrm{Cu}-\mathrm{H}_{2} \mathrm{O}$ bond length is of 2.156(2) $\AA$ and thus is similar as in 2 [16]. The $\mathrm{Cu}-\mathrm{O}$ bond lengths are of $1.96-2.15 \AA$ and the $\mathrm{Cu}-\mathrm{N}$ bond lengths are of $2.01-2.03 \AA$. The Addison $\tau$ parameter defined as $\tau=(\beta-\alpha) / 60$ for $\alpha$ O3-Cu1-O1 85.69(18) and $\beta$ O1-Cu1-N2 149.17(15) is 1.058 , thus the coordination sphere is trigonal bipyramidal [17].

In the crystal structure hydrogen bonds of the $\mathrm{O}-\mathrm{H} \cdots \mathrm{O}$ type are present. They not only stabilize the crystal structure but also might assist in transmission of magnetic exchange

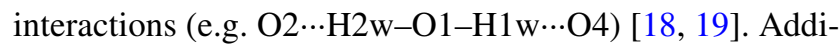
tionally the hydrogen bonds link the 2D coordination polymer layers to form a 3D network (Fig. 5). The parameters of the corresponding hydrogen bonds are listed in Supplementary Table S6.

\subsection{Other Properties}

$\mathbf{1}$ and $\mathbf{2}$ were characterized with a number of methods (see Experimental for elemental analyses and IR bands assignment). Also thermal decomposition under nitrogen atmosphere and the magnetic properties of $\mathbf{2}$ were investigated.

\subsubsection{Thermal Decomposition}

The thermal decomposition for both compounds was investigated at $40-1200{ }^{\circ} \mathrm{C}$ temperature range under nitrogen atmosphere (Supplementary pages 5 and 11). Experimental TGA data are presented in the Supplementary Material (Figs. S4 and S5). For the ligand 1 a 4-step decomposition process is observed. The first endothermal step at $190{ }^{\circ} \mathrm{C}$ involves evolution of water molecules (exp. 6.40\%, calc. $6.86 \%$ ). The second endothermal step is observed at $400{ }^{\circ} \mathrm{C}$ and may involve decarboxylation (exp. $10.84 \%$, calc. $12.39 \%$ ). The third peak at $600^{\circ} \mathrm{C}$ most probably involves further degradation of the ligand organic part. The last exothermal peak at $900{ }^{\circ} \mathrm{C}(\exp 11.43 \%)$ involves decomposition of the remaining organic part. 
Fig. 2 One of the graph set motifs in 1: $R_{4}^{4}$ (14). (Color figure online)

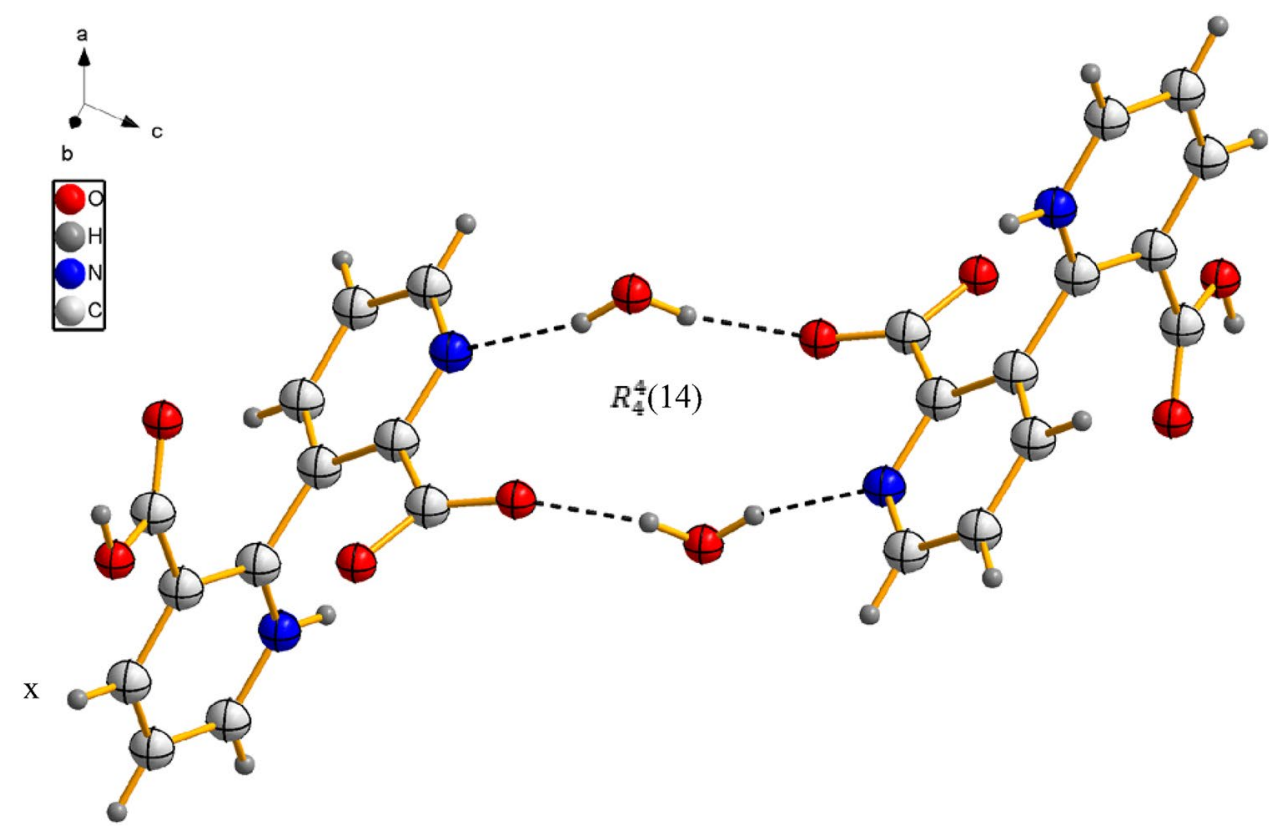

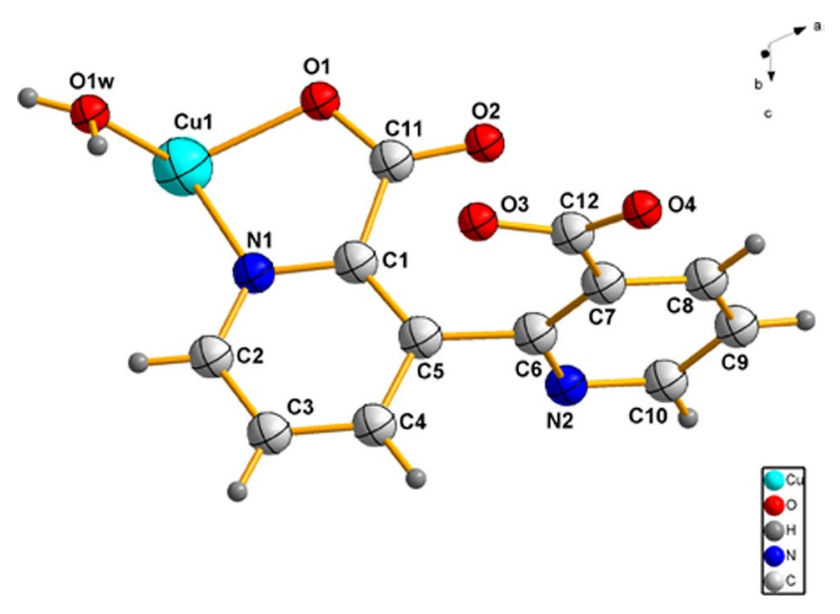

Fig. 3 Symmetry-independent part of 2 . (Color figure online)

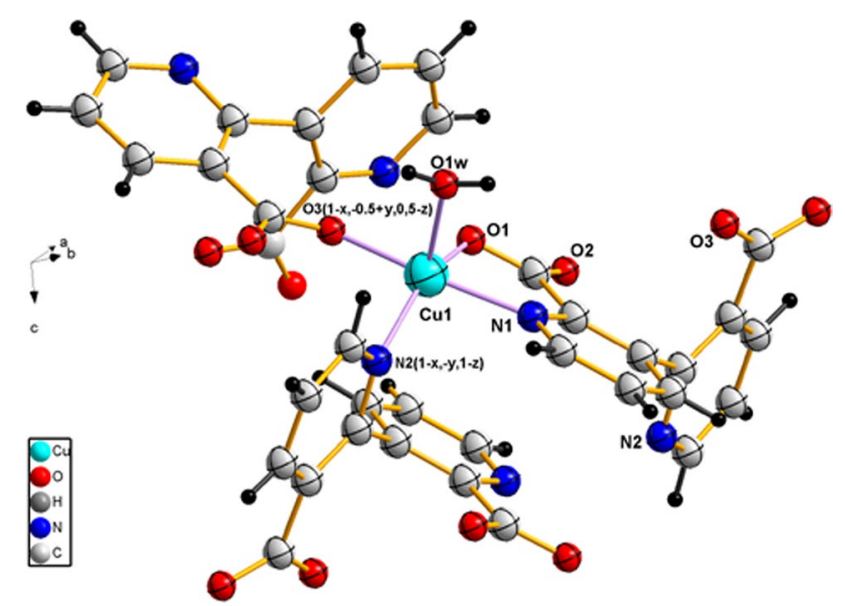

Fig. 4 Coordination sphere of the $\mathrm{Cu}^{2+}$ ion in 2. (Color figure online)

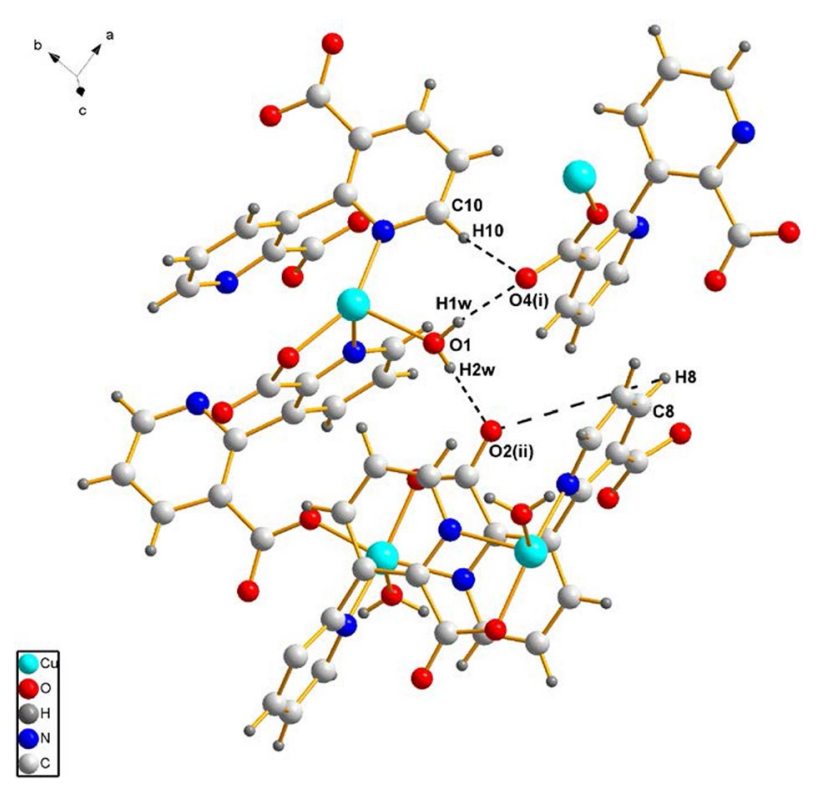

Fig. 5 Hydrogen bonds system in the coordination polymer 2. (Color figure online)

For the polymer 2 a 3 -step decomposition process is observed. The first endothermal peak at $220{ }^{\circ} \mathrm{C}$ may correspond to the $\mathrm{C}_{12} \mathrm{~N}_{2} \mathrm{O}_{2}$ moiety (exp. $58.99 \%$, calc. $61.01 \%$ ). The second endothermal peak at $420{ }^{\circ} \mathrm{C}$ involves decarboxylation (exp. $21.39 \%$, calc. $27.18 \%$ ). The last exothermal peak at ca. $1000{ }^{\circ} \mathrm{C}$ should correspond to decomposition of the remaining part, leading to a mixture of $\mathrm{Cu}$ oxides as residue. 


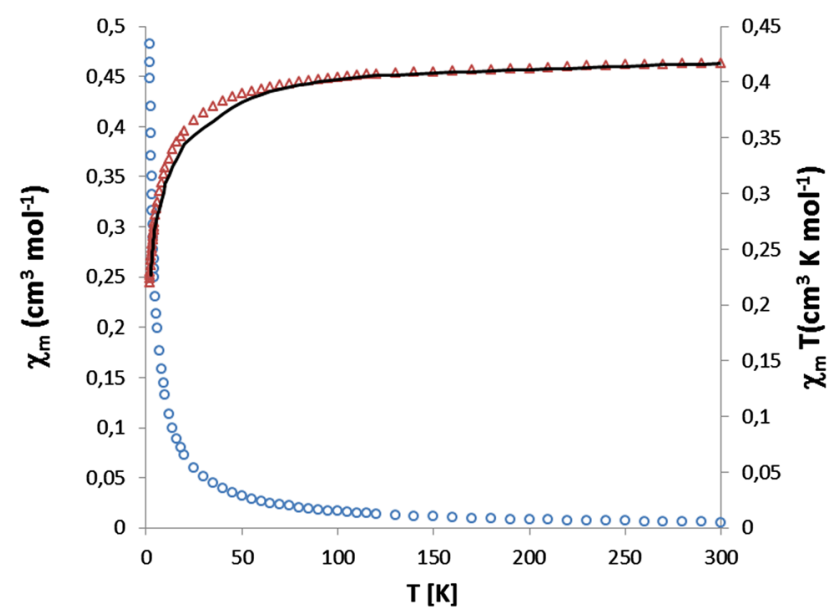

Fig. 6 Temperature dependence of the molar magnetic susceptibility $\chi_{m}$ (open circle) and the $\chi_{m} T$ product (triangle) for $\mathrm{Cu} 2$ complex, calculated per one $\mathrm{Cu}$ (II) center. Solid lines are calculated curves with parameters presented in the text

\subsubsection{Magnetic Properties}

Magnetic susceptibilities of the complex 2 were measured in an applied magnetic field $\mathrm{H}=0.5 \mathrm{~T}$ in the temperature range $1.8-300 \mathrm{~K}$. As shown in Fig. 6 the $\chi_{\mathrm{m}} \mathrm{T}$ value at $300 \mathrm{~K}$ is of $0.416 \mathrm{~cm}^{3} \mathrm{~K} \mathrm{~mol}^{-1}$ and decreases to $0.221 \mathrm{~cm}^{3} \mathrm{~K} \mathrm{~mol}^{-1}$ at $1.8 \mathrm{~K}$. In general, from $80 \mathrm{~K}$ the $\chi_{\mathrm{m}} \mathrm{T}$ values decrease which may correspond to antiferromagnetic interactions between the neighbouring $\mathrm{Cu}^{2+}$ ions in the coordination polymer. For measurements of the susceptibility data good fit to the Curie-Weiss law $\left(\chi_{\mathrm{m}}=\mathrm{C} /(\mathrm{T}-\Theta)\right)$ was achieved, giving Curie $(C)$ and Weiss $(\Theta)$ constants of $0.58 \mathrm{~cm}^{3} \mathrm{~K} \mathrm{~mol}^{-1}$ and $-1.70 \mathrm{~K}$, respectively.

The magnetic data for $\mathbf{2}$ were fitted using the magnetic chain model corresponding to the equation [20]:

$\chi_{\mathrm{m}}=\frac{N \beta^{2} g^{2} S(S+1)}{3 k T} \frac{1+u}{1-u}$

$u=\operatorname{coth}\left[\frac{J S(S+1)}{k T}-\frac{k T}{J S(S+1)}\right]$

The best fit to the experimental data leads to the following values: $\mathrm{J}=-0.37 \mathrm{~cm}^{-1}, \mathrm{~g}=2.15$ and $\mathrm{R}=2.97 \times 10^{-5}$. $\mathrm{R}$ is the agreement coefficient defined by the equation:

$R=\sum_{n}^{l}\left(\chi_{i}^{\exp }-\chi_{i}^{\text {calc }} T\right)^{2} /\left(\chi_{i}^{\exp } T\right)^{2}$

Temperature dependence of the molar magnetic susceptibility $\chi_{m}(O)$ and $\chi_{m} T$ are presented in Fig. 6 . The closest interatomic $\mathrm{Cu} \cdots \mathrm{Cu}$ distances are 5.668(5) $\AA$.

Analysis of the crystal structure leads to the conclusion that most probable magnetic interactions pathway is through hydrogen bonds involving water molecules: $\mathrm{Cu} 1{ }^{\mathrm{i}}-\mathrm{O} 1^{\mathrm{i}}-\mathrm{C} 11^{\mathrm{i}}-\mathrm{O} 2^{\mathrm{i}} \cdots \mathrm{H} 2 \mathrm{w}-\mathrm{O} 1 \mathrm{w}-\mathrm{Cu} 1$ $(\mathrm{i}=\mathrm{x},-0.5-\mathrm{y},-0.5+\mathrm{x})$.

The proposed pathway is illustrated in the Figure below, displaying the closest $\mathrm{Cu} \cdots \mathrm{Cu}$ distances (Fig. 7.).

Similar properties were observed by Decurtins et al. for 1D antiferromagnetic metal-organic framework $[\mathrm{Cu}(\mathrm{DCMB})(\mathrm{CA})]_{\mathrm{n}}$ where DCMB is $3.3^{\prime}$-dicarbomethoxy2,2'-bipyridyl and CA is dianion of chloroanilic acid [21].

The exchange coupling constant (2J) value was estimated to be $-0.31 \mathrm{~cm}^{-1}$.

In a different coordination polymer reported by Jan et al. $\left\{\left[\mathrm{Cu}_{2}(\text { bzgluO })_{2}(\text { bpe })_{2}\right] \cdot 7 \mathrm{H}_{2} \mathrm{O}\right\}_{\mathrm{n}}$, where an $\mathrm{N}$-donor ancillary ligand is $\mathrm{H}_{2}$ bzgluO $=N$-benzoyl-L-glutamic acid, bpe $=1,2$-bis(4-pyridyl)ethane, the best fitting parameter obtained is $\mathrm{J}=-0.85$. The negative $\mathrm{J}$ value indicates that there is a weak antiferromagnetic interaction in the investigated complex [22].

Superexchange interactions through hydrogen bonds have been already observed in such copper(II) compounds as e.g. copper(II) complex, $[\mathrm{Cu}(\mathrm{LH})(\mathrm{L})] \cdot \mathrm{BF}_{4} \cdot 2 \mathrm{H}_{2} \mathrm{O}(\mathrm{LH}=N$-tertbutyl- $N$-2-pyridylhydroxylamine) - in this case the magnetic interactions pathway was found to be $\mathrm{Cu}-\mathrm{O}-\mathrm{H} \cdots \mathrm{O}-\mathrm{Cu}$ $(\mathrm{Cu} \cdots \mathrm{Cu}$ distance at 4.4669(12) $\mathrm{A})$ [23].

Other examples are $\left[\mathrm{Cu}\left(\mathrm{H}_{2} \mathrm{O}\right)\left(\mathrm{C}_{7} \mathrm{H}_{6} \mathrm{~N}_{2}\right)_{2}\left(\mathrm{C}_{6} \mathrm{H}_{6} \mathrm{O}_{4}\right)\right]$ and isostructural $\left[\mathrm{Cu}\left(\mathrm{H}_{2} \mathrm{O}\right)\left(\mathrm{C}_{7} \mathrm{H}_{6} \mathrm{~N}_{2}\right)_{2}\left(\mathrm{C}_{6} \mathrm{H}_{8} \mathrm{O}_{4}\right)\right]\left(\mathrm{C}_{7} \mathrm{H}_{6} \mathrm{~N}_{2}\right.$-benzimidazole, $\mathrm{C}_{6} \mathrm{H}_{6} \mathrm{O}_{4}$-trans-2-butene-1,4-dicarboxylic acid) with antiferromagnetic interactions transmitted through a network of hydrogen bonds ( $\mathrm{Cu} . . . \mathrm{Cu}$ distances at 11.2383(6) and 10.926(1) A, respectively) [24].

Gasque et al. used reaction between 2,8-dimethyl5,11-bis(pyridine-2-ylmethyl)-1,4,5,6,7,10,11,12octahydroimidazo[4,5-h]imidazo-[4,5-c] [1,6]-diazecine

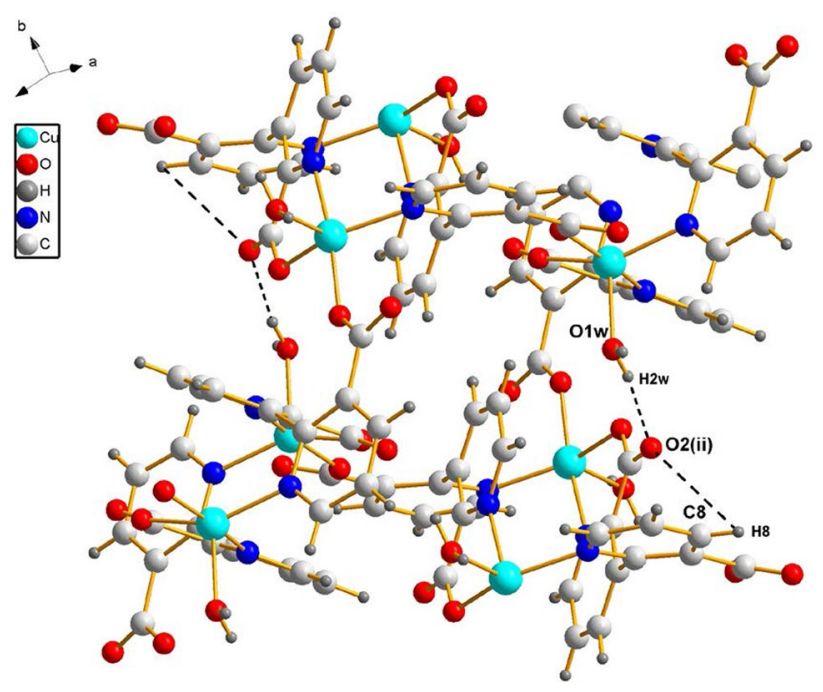

Fig. 7 Proposed pathway of the magnetic interactions in the studied coordination polymer $\left(\mathrm{Cu}-\mathrm{COO} \cdots \mathrm{H}_{2} \mathrm{O} \cdots \mathrm{H}_{2} \mathrm{O}-\mathrm{Cu}\right.$ ). (Color figure online) 
(dimp) with copper(II) nitrate in water to obtain $\left[\mathrm{Cu}_{2}(\operatorname{dimp})\left(\mathrm{H}_{2} \mathrm{O}\right)_{2}\left(\mathrm{NO}_{3}\right)_{2}\right]\left(\mathrm{NO}_{3}\right)_{2}$ complex, also appearing to be the case of magnetic interactions transmission through hydrogen bonds ( $\mathrm{Cu}$... Cu distance at 6.255(2) $\AA$ ) [25].

\subsubsection{EPR Spectra}

Powder EPR spectrum of the compound 2 recorded at $77 \mathrm{~K}$ shows a broad asymmetric band with simulated tensor values of $g_{\perp}=2.08, g_{\|}=2.21$ (see Fig. 8). For coordination number 5 the possible border coordination geometries are trigonal bipyramidal (TBP) or square pyramidal (SP). The transition between them may occur as the energetic barrier is low for the ground state $\mathrm{d}_{\mathrm{z}}^{2}$, especially in solution [26, 27].

Broadening and extension of the spectrum is caused by interactions with the ${ }^{14} \mathrm{~N}$ nuclei. The fact that $g_{\|}>2.1>g_{\perp}>2.0$ is connected with the distorted trigonal bipyramidal coordination environment of the $\mathrm{Cu}^{2+}$ ion $\left(\mathrm{D}_{3 \mathrm{~h}}\right)$.

The obtained $g$ values are characteristic for the related metal complexes with chromophore $\mathrm{N}_{2} \mathrm{O}_{2}$ groups. $\mathrm{M}$. Padmanabhan et al. obtained the coordination polymer $\left[\mathrm{Cu}(\mathrm{ipt})\left(\text { dap) } \mathrm{H}_{2} \mathrm{O}\right]_{\mathrm{n}} \cdot \mathrm{nH}_{2} \mathrm{O}\right.$ with isophthalate (ipt) as bridging moieties and chelating ligand 1,3-diaminopropane (dap) with similar $\mathrm{Cu}^{2+}$ coordination environment as in 2 for which $\mathrm{g}_{\|}=2.158$ and $\mathrm{g}_{\perp}=2.074$ values were observed [28]. Higher $g_{\perp}>2.04$ values are detected for the majority

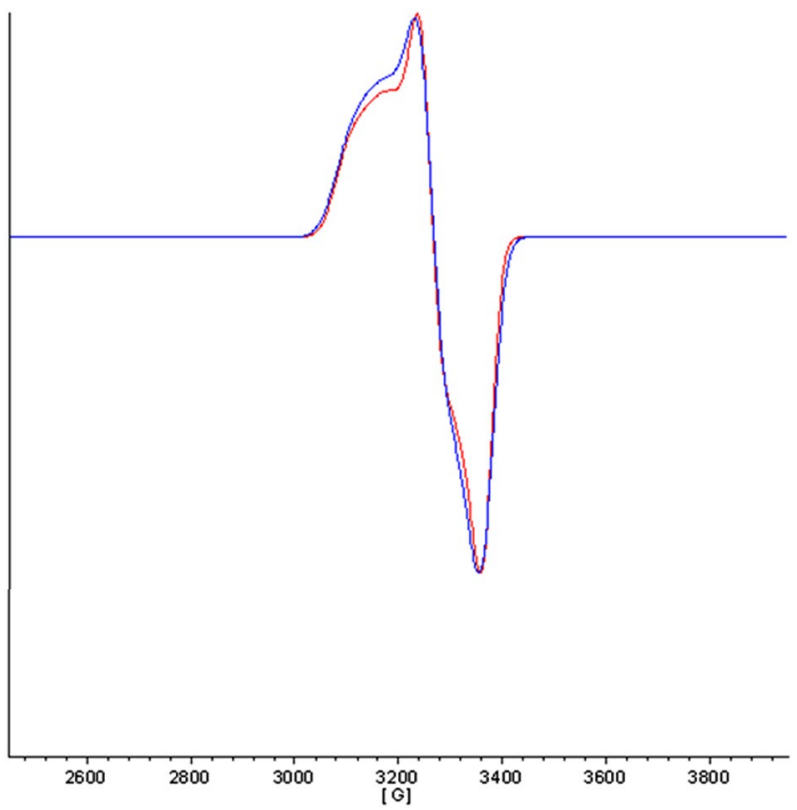

Fig. 8 Powder EPR spectra of the compound 2 at $77 \mathrm{~K}$, the red line is the theoretical one. (Color figure online) of complexes with metal coordination environment of distorted trigonal bipyramidal symmetry [29].

\subsubsection{Photoluminescence Spectra}

The luminescent properties of $\mathbf{1}$ and $\mathbf{2}$ were explored in the solid state at room temperature (see Fig. 9). For the free ligand one emission band is observed with maxima at 385 and $401 \mathrm{~nm}$. A band is formed by two constituents overlapping which can be assigned to charge-transfer and $\pi \cdots \pi^{*}$ transitions, respectively. For the coordination polymer 2 an emission band with a maximum at $482 \mathrm{~nm}$ is connected with blue-green emission (475-580 $\mathrm{nm}$ ) attributed to ligand-to-metal charge transfer (LMCT) transition between the delocalized $\pi$ electron density of the ligand and $\mathrm{Cu}$ (II) $d$ orbitals. As a result, the emission can be assigned to the chelation of the carboxylate and bpy ligands to the central ions.

Transition metal complexes with the related ligands were considered for applications in organic light-emitting diodes (OLEDs) [30]. It could be expected that targeted modification of the compound $\mathbf{2}$ could improve its luminescence properties.

Similar spectra were recorded by Ji et al. for the $\{[\mathrm{Cu}$ (bptc) $\left.\left.{ }_{0.5}\left(\mathrm{H}_{2} \mathrm{O}\right)\right] \cdot \mathrm{H}_{2} \mathrm{O}\right\}_{n}$ coordination polymer with bptcH ligand $\left(\mathrm{bptcH}_{4}=2,2^{\prime}\right.$-bipyridine-3,3',6,6'-tetracarboxylic acid) [31]. For the $\mathrm{Cd}(\mathrm{II})$ and $\mathrm{Zn}$ (II) coordination polymers with polypyridyl ligand the emission bands were found at 440-540 nm [32-35]. Yan-Zhi Tang et al. carried out hydrothermal syntheses using 2,2'-bipyridine3,3'-dicarboxylic acid ligand to detect fluorescent emission fort the coordination polymer $\{[\mathrm{Cu}(\mathrm{BDCD})] \cdot \mathrm{EtOH}\}_{\mathrm{n}}$ where BDCB is anion of 2,2'-bipyridine-3,3'-dicarboxylic acid-1,1'-dioxide [36].

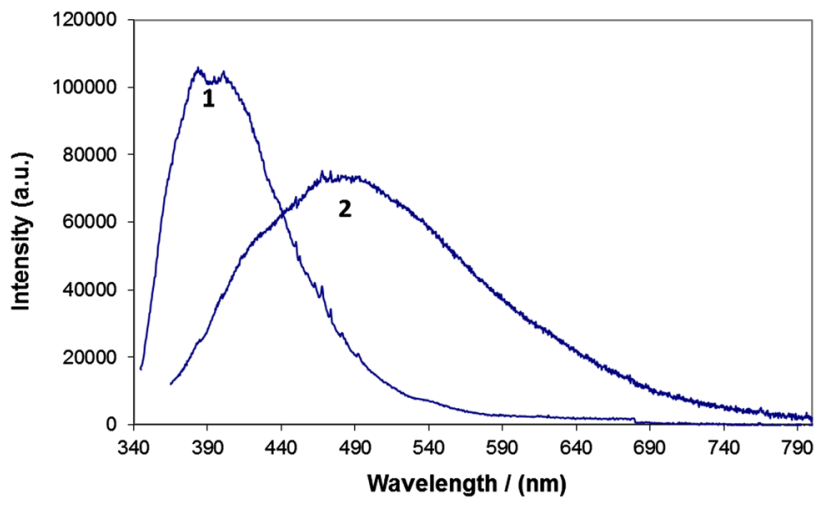

Fig. 9 Photoluminescence emission spectra excited with $385 \mathrm{~nm}(1)$ and $401 \mathrm{~nm}$ (2) of the ligand 1 and the polymer 2 with $482 \mathrm{~nm}$ in solid state at $297 \mathrm{~K}$ 


\section{Conclusions}

A new ligand 2,3'-bipyridine-2',3-dicarboxylic acid monohydrate (1) and its copper(II) 2D coordination polymer $\left[\mathrm{Cu}\left(2,3^{\prime}-2^{\prime}, 3-\text { bpdc }\right) \mathrm{H}_{2} \mathrm{O}\right]_{\mathrm{n}}(2)$ were synthesized. Both $\mathbf{1}$ and 2 show photoluminescent properties confirmed with the corresponding emission spectra. For $\mathbf{2}$ the antiferromagnetic interactions between the $\mathrm{Cu}^{2+}$ ions may be transmitted also through hydrogen bonds. Based on this work the use of a Berghoff autoclave for reproducible solvothermal syntheses is demonstrated. The use of well-designed ligands in this method may lead to more useful photoluminescent products.

Acknowledgements Dr J. Trojan-Piegza for recording luminescent spectra and discussion, Dr hab. J. Wojaczyński for recording of NMR spectra and discussion.

Disclosure No potential conflict of interest is reported by the authors.

Open Access This article is distributed under the terms of the Creative Commons Attribution 4.0 International License (http://creativecommons.org/licenses/by/4.0/), which permits unrestricted use, distribution, and reproduction in any medium, provided you give appropriate credit to the original author(s) and the source, provide a link to the Creative Commons license, and indicate if changes were made.

\section{References}

1. S. Kitagawa, R. Kitaura, S.I. Noro, Angew. Chem., Int. Ed. 43, 2334 (2004)

2. M. Hołyńska, J. Kołodziejczak, A. Kochel, Inorg. Chim. Acta 436, 214 (2015)

3. A. Kochel, M. Hołyńska, Inorg. Chim. Acta 408, 193 (2013)

4. S. Sanram, J. Boonmak, S. Youngme, Inorg. Chim. Acta 469, 11 (2018)

5. X.-Y. Cao, Q.-P. Lin, Y.-Y. Qin, J. Zhang, Z.-J. Li, J.-K. Cheng, Y.-G. Yao, Cryst. Growth Des. 9, 20 (2009)

6. A. Sasmal, E. Garribba, C. Rizzoli, S. Mitra, Inorg. Chem 53, $6665(2014)$

7. A. Kochel, M. Hołyńska, Acta Crystallogr. C67, m137 (2011)

8. Agilent, CrysAlis PRO (Agilent Technologies Ltd, Yarnton, 2014)

9. G.M. Sheldrick, Crystal structure solution and refinement with SHELXT, SHELXL. Acta Crystrallogr. C71, 3 (2016)

10. WINEPR SimFonia Version 1.26, Copyright (1994-97), Bruker analytical $\mathrm{GmbH}$

\section{Affiliations}

\section{Kamil Twaróg ${ }^{1}$. Małgorzata Hołyńska ${ }^{2}$. Andrzej Kochel ${ }^{1}$}

1 Department of Chemistry, Wrocław University, F. Joliot Curie 14, 50383 Wrocław, Poland
11. E. König, Magnetic Properties of Coordination and Organomettalic Transition Metal Compounds. (Springer, Berlin, 1966)

12. M.S. Caceci, Anal. Chem. 61, 2324 (1989)

13. M. Hołyńska, A. Filarowski, A. Kochel, K. Twaróg, J. Chem. Crystallogr. 45, 363 (2015)

14. R. Custelcean, M.G. Gorbunova, Cryst. Eng. Commun. 7, 297 (2005)

15. L.-Y. Zhang, L.-P. Lu, S.-S. Feng, Acta Crystallogr. C72, 652 (2016)

16. F. Gracia, J. Perles, F. Zamora, P. Amo-Ochoa, Inorg. Chim. Acta 453, 574 (2016)

17. A.W. Addison, T.N. Rao, J. Reedijk, J. van Rijn, G.C. Verschoor, J. Chem. Soc. Dalton Trans. (1984). https://doi.org/10.1039/ DT9840001349

18. S.I. Levchenkov, I.N. Shcherbakov, L.D. Popov, V.V. Lukov, V.V. Minin, Z.A. Starikova, E.V. Ivannikova, A.A. Tsaturyan, V.A. Kogan, Inorg. Chim. Acta 405, 169 (2013)

19. Z. Vasková, J. Moncol, M. Korabik, J. Medvecká, J. Švorec, Z. Padelková, M. Valko, D. Valigura, Polyhedron 30, 86 (2011)

20. O. Kahn, Molecular Magnetism. (VCH Publishers, New York, 1993)

21. S. Decurtins, H.W. Schmalle, L.-M. Zheng, J. Ensling, Inorg. Chim. Acta 244, 165 (1996)

22. M.-J. Yan, Q. Feng, H.-H. Song, H.-T. Yu, Inorg. Chim. Acta 450, 304 (2016)

23. A. Okazawa, T. Ishida, Chem. Phys. Lett. 480, 198 (2009)

24. L. Sieroń, M. Bukowska-Strzyżewska, M. Korabik, J. Mroziński, Polyhedron 21, 2479 (2002)

25. J. Sánchez Costa, N.A.G. Bandeira, B. Le Guennic, V. Robert, P. Gamez, G. Chastanet, L. Ortiz-Frade, L. Gasque, Inorg. Chem. 50, $5696(2011)$

26. R. Barbucci, A. Bencini, D. Gatteschi, Inorg. Chem. 16, 2117 (1997)

27. B.A. Bencini, D. Gatteschi, Inorg. Chem. 16, 1994 (1977)

28. M. Padmanabhan, K.C. Joseph, A. Thirumurugan, X. Huang, T.J. Emge, J. Li, Inorg. Chim. Acta 360, 2583 (2007)

29. B.J. Hathaway, D.E. Billing, Coord. Chem. Rev. 5, 143 (1970)

30. H. Xu, R. Chen, Q. Sun, W. Lai, Q. Su, W. Huang, X. Liu, Chem. Soc. Rev. 43, 3259 (2014)

31. B. Ji, D. Deng, X. He, X. Fan, G. Qu, Inorg. Chim. Acta 416, 102 (2014)

32. C.-G. Zheng, Y.-L. Xie, R.-G. Xiong, X.-Z. You, Inorg. Chem. Commun. 4, 405 (2001)

33. J. Zhang, Y.-R. Xie, Q. Ye, R.-G. Xiong, Z.-L. Xue, X.-Z. You, Eur. J. Inorg. Chem. 14, 2572 (2003)

34. J.-H. Luo, M.-C. Hong, R.-H. Wang, R. Cao, L. Han, Z.-Z. Lin, Eur. J. Inorg. Chem. 2705 (2003)

35. L. Han, M.-C. Hong, R.-H. Wang, J.-H. Luo, Z.-Z. Lin, D.-Q. Yuan, Chem. Commun. 2580 (2003)

36. Y.Z. Tang, M. Zhou, H.-R. Wen, Z. Cao, X.-W. Wang, S. Huang, CrystEngComm 13, 3040 (2011)
2 Fachbereich Chemie and Wissenschaftliches Zentrum für Materialwissenschaften, Philipps-Universität Marburg, Hans-Meerwein-Straße, 35043 Marburg, Germany 